\title{
Seasonal variations in lower stratospheric gravity wave energy above the Falkland Islands
}

\author{
T. Moffat-Griffin, ${ }^{1}$ M. J. Jarvis, ${ }^{1}$ S. R. Colwell, ${ }^{1}$ A. J. Kavanagh, ${ }^{1}$ G. L. Manney, ${ }^{2,3}$ \\ and W. H. Daffer ${ }^{4}$ \\ Received 12 December 2012; revised 11 September 2013; accepted 17 September 2013; published 4 October 2013.
}

[1] The gravity wavefield in the lower stratosphere (between $15 \mathrm{~km}$ and $22 \mathrm{~km}$ altitude) above Mount Pleasant Airport $\left(51^{\circ} 49^{\prime} \mathrm{S}, 58^{\circ} 26^{\prime} \mathrm{W}\right)$ on the Falkland Islands is studied using over 2100 high-resolution radiosonde soundings from 2002 to 2010 . The seasonal variation in vertical direction of propagation shows a small decrease in numbers of upward propagating waves that is related to critical level filtering; however, there is a very large increase in numbers of downward propagating waves between July and September; this is attributed to the proximity of the edge of the polar vortex. There is a seasonal variation in gravity wave energy density, with a large peak during the austral autumn equinox; this is markedly different to results in the literature both from Rothera, on the Antarctic Peninsula, and stations on the main Antarctic continent. This seasonal pattern has been shown to be linked to variations in the sources of upward propagating gravity waves. The seasonal variation in gravity wave characteristics above Mount Pleasant Airport seen in our results suggests that the gravity wavefield in this region is determined by a combination of different gravity wave sources located above and below the lower stratosphere.

Citation: Moffat-Griffin, T., M. J. Jarvis, S. R. Colwell, A. J. Kavanagh, G. L. Manney, and W. H. Daffer (2013), Seasonal variations in lower stratospheric gravity wave energy above the Falkland Islands, J. Geophys. Res. Atmos., 118, 10,861-10,869, doi:10.1002/jgrd.50859.

\section{Introduction}

[2] Gravity waves are short-period (ranging from a few minutes to a day at high to midlatitudes [Alexander et al., 2002]), small spatial scale (horizontal wavelengths from several to a few hundred kilometres) buoyancy waves in the atmosphere that strongly influence the large-scale dynamics of the middle atmosphere through momentum and energy deposition. Short scale gravity waves cannot be properly resolved in global circulation models (especially climate models, which tend to have lower resolution) due to their small spatial scale in comparison to the model resolution; they are therefore represented by parameterizations. The type of parameterization implemented in a model can be orographic, nonorographic, or a combination of the two. The majority of these parameterizations are fixed in their effect, i.e., they do not react to changes in the surrounding atmosphere that can affect gravity wave activity, e.g., cyclonic activity. However, work is progressing within the community on developing more

\footnotetext{
${ }^{1}$ British Antarctic Survey, High Cross, Cambridge, UK.

${ }^{2}$ NorthWest Research Associates, Socorro, New Mexico, USA.

${ }^{3}$ Now at New Mexico Institute of Mining and Technology, Socorro, New Mexico, USA.

${ }^{4}$ Jet Propulsion Laboratory, California Institute of Technology, Pasadena, California, USA.

Corresponding author: T. Moffat-Griffin, British Antarctic Survey, High Cross, Madingley Road, Cambridge CB3 0ET, UK. (tmof@bas.ac.uk)

(C)2013. American Geophysical Union. All Rights Reserved. 2169-897X/13/10.1002/jgrd.50859
}

responsive nonorographic gravity wave parameterizations [Alexander et al., 2010; Kim et al., 2003].

[3] Data on the nature of the gravity wave activity, including seasonal variability and intermittency, over different locations will aid the refinement and development of future gravity wave parameterizations.

[4] The Falkland Islands are located off the south east coast of South America and are $\sim 1200 \mathrm{~km}$ north of the Antarctic Peninsula. The Falkland Islands, along with the tip of South America, the Drake Passage, and Antarctic Peninsula are located under a region of intense stratospheric gravity wave activity, known as a "hot spot," that has been observed in satellite studies [Alexander and Teitelbaum, 2011; Hei et al., 2008; McLandress et al., 2000; Preusse et al., 2009; Wu and Jiang, 2002]. However, all instruments suffer from what is known as observational filtering, so no single instrument is able to observe the entire gravity wave spectrum [Alexander, 1998]. Using a combination of different instruments, both satellite-based and ground-based, will allow more comprehensive observations of the majority of the gravity wave spectrum to be made. The gravity wave activity over the Falkland Islands has only been studied as part of the satellite "hot spot" studies previously mentioned; there have been no ground-based studies of gravity wave activity over the Falkland Islands. Some studies of orographic turbulence over the Falkland Islands have been undertaken, such as studies of rotors, which are related to gravity wave generation 


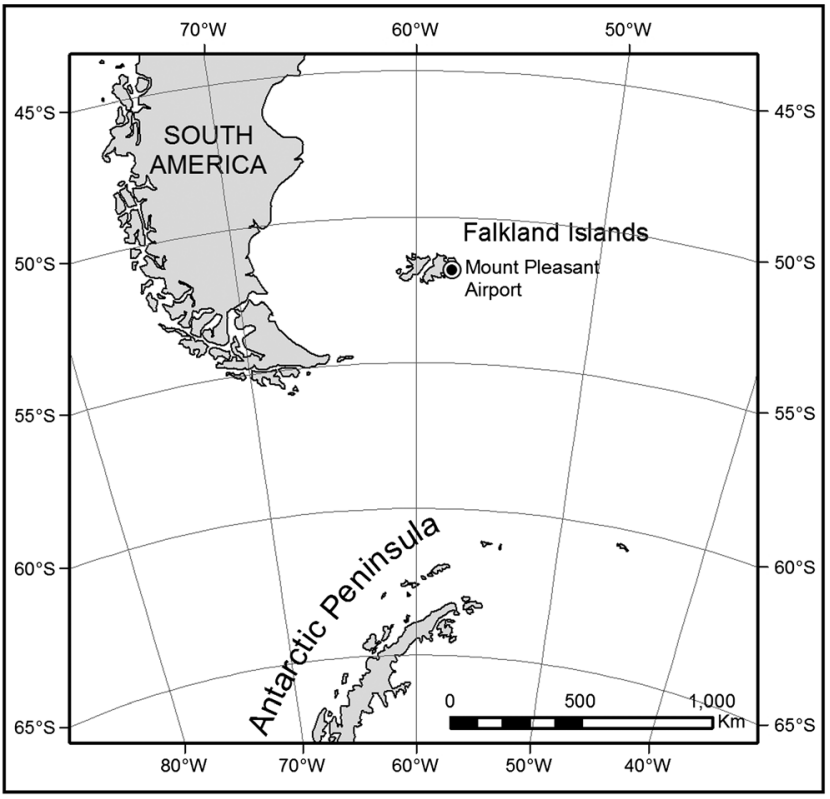

Figure 1. Map showing the position of the Falkland Islands relative to the Antarctic Peninsula and South America. The position of Mount Pleasant Airport on the Islands is marked.

[Mobbs et al., 2005; Sheridan and Vosper, 2005; Vosper, 2004]. These studies focused on a small area of the Falklands and did not examine the stratosphere.

[5] Radiosondes provide a reliable method of observing and quantifying gravity waves and there have been high-resolution radiosondes launched twice a day from Mount Pleasant Airport (hereafter MPA) since 1999. MPA is located on East Falkland (see Figure 1) and lies to the south of an east-west orientated ridge of large hills (the Wickham Heights). This paper will discuss the seasonal variation in gravity wave activity in the lower stratosphere above MPA derived using these radiosonde data. Possible gravity wave sources are identified and their seasonal variability is linked to the variability seen in gravity wave generation and dissipation processes. For comparison purposes with a previous study [Moffat-Griffin et al., 2011], and to avoid diurnal variability, which is anyway expected to be small in this region [Pirscher et al., 2010], the launches at 11UT were selected for this study. The results in this paper are from data recorded between 1 January 2002 and 31 December 2010 at (or close to) $11 \mathrm{UT}$; there were a total of 2295 balloon launches, but only 2127 complied with the analysis constraint for this paper of only including data from radiosondes that reached at least $22 \mathrm{~km}$ altitude.

\section{Data}

[6] High-resolution radiosondes have been launched twice daily by the Met Office from MPA since 1999, [BADC, 2012]. The launches usually occur at 11UT and 23UT, although they may vary by $\pm 1 \mathrm{~h}$, with the radiosondes recording data every $2 \mathrm{~s}$ during their ascent. The data returned consist of vertical profiles of pressure, temperature, relative humidity, specific humidity, wind speed, and wind direction from the surface to the balloon burst height, around
$20-30 \mathrm{~km}$ altitude. The wind speed and direction are determined using the GPS positioning device built into the radiosonde. The Vaisala RS80-H radiosonde was used at MPA until 2005 and from 2006 to date the Vaisala RS92 radiosonde is used. Before replacing the RS80-H with the RS92, its data output was extensively tested by the Met Office in conjunction with Vaisala to ensure data quality and consistency across the two data sets [Smout et al., 2005].

[7] The maximum height reached by each radiosonde launch from MPA at (or close to) 11UT is shown in Figure 2. Between 2000 and 2008, there is a distinct seasonal variation in the height reached. This variation becomes less distinct from 2008 onward. This is because mid-2008 the Met Office switched from using $800 \mathrm{~g}$ balloons to $350 \mathrm{~g}$ balloons and from April 2009 they switched to using $100 \mathrm{~g}$ balloons. These lighter balloons do not reach to such high altitudes as the $800 \mathrm{~g}$ balloons before they burst and thus the distinct seasonal variation is less pronounced because they reach a more consistent, but lower, height over the course of the year, [Personal Communication with Gemma Holmes, Met Office].

\section{Gravity Wave Analysis}

\subsection{Energy}

[8] The kinetic and potential energy per unit mass of the gravity waves on a given day are determined from wind and temperature perturbations from the radiosonde profiles using the same process as Moffat-Griffin et al. [2011]. Data are interpolated onto a $50 \mathrm{~m}$ height grid then the first-order perturbations of the profile are calculated [Vincent and Alexander, 2000].

[9] For this paper, an altitude range of $15-22 \mathrm{~km}$ is studied; this is to enable comparison with other relevant studies in the literature [Moffat-Griffin et al., 2011; Yoshiki and Sato, 2000]. The wave energy from each individual radiosonde profile over the required height range is calculated following the technique and equations described in Vincent et al. [1997]:

$$
E_{0}=\frac{1}{2}\left[\overline{u^{\prime 2}}+\overline{v^{\prime 2}}+\frac{g^{z} \overline{\hat{T}^{\prime z}}}{N^{z}}\right]
$$

[10] The first two terms in the equation represent the kinetic energy per unit mass (determined using the unweighted average over height of the zonal and meridional components of the wind squared $\left(\overline{u^{\prime 2}}\right.$ and $\left.\overline{\mathrm{v}^{\prime 2}}\right)$ ); the vertical wind speed perturbations have not been included because they are small

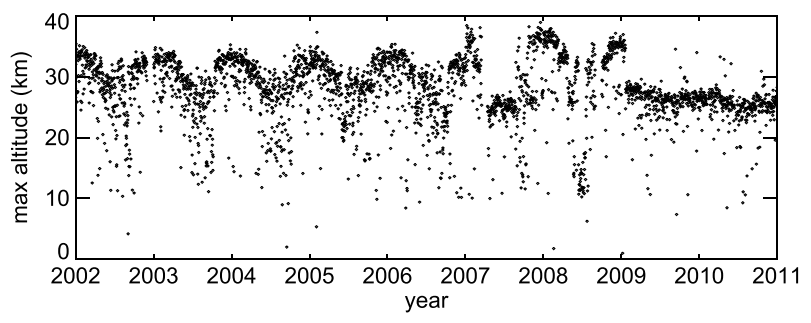

Figure 2. Altitude above MPA at which the radiosondes balloons burst. 


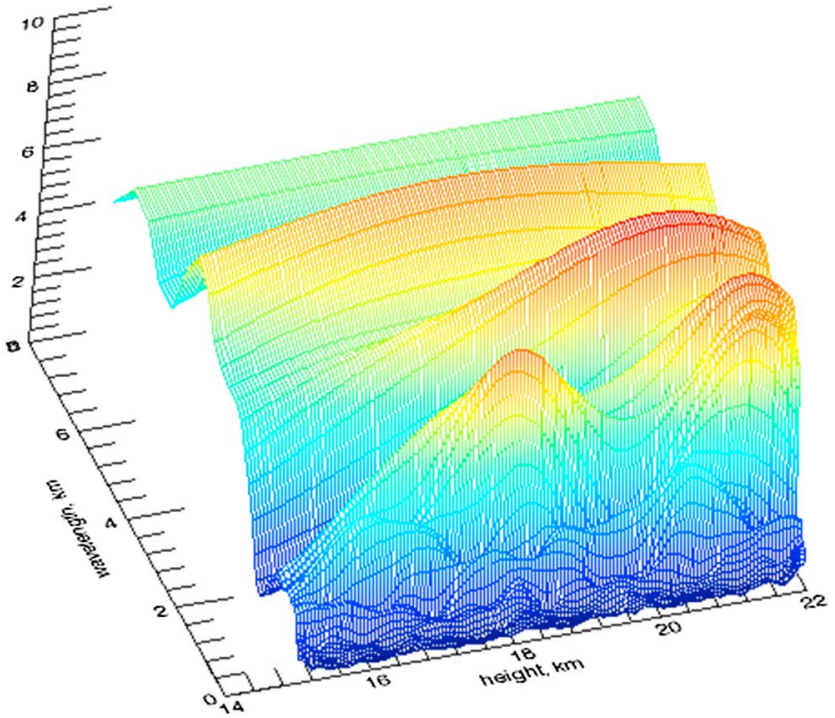

Figure 3. Surface plot of the modulus of a wavelet transform as a function of wavelength and altitude. The data used are from a MPA radiosonde wind profile from 3 July 2002 between $15 \mathrm{~km}$ and $22 \mathrm{~km}$ altitude. Four wave packets are observed in the profile. The $\mathrm{x}$-axis is height in $\mathrm{km}$ and the $\mathrm{y}$-axis is wavelength in $\mathrm{km}$.

compared to the horizontal wind speed perturbations (e.g., mean perturbation values of $0.01 \mathrm{~ms}^{-1}$ compared to $1.7 \mathrm{~ms}^{-1}$ ), and thus will not have a significant contribution to the energy density total. The last term in equation 1 represents the potential energy per unit mass (determined using the Brunt Vaisala frequency $(\mathrm{N})$ and the unweighted average over height of the normalized temperature fluctuation $\left(\overline{\hat{T}^{\prime 2}}\right)$ ), [Vincent et al., 1997].

\subsection{Propagation Direction}

[11] An individual radiosonde profile usually can contain multiple gravity waves rather than just a single monochromatic wave. This can make the derived gravity wave parameters (e.g., propagation direction) from the radiosonde profiles difficult to interpret as the signatures of multiple waves can be mixed together.

[12] Work done by Zink and Vincent [2001] showed that it was possible to isolate the individual waves in a profile using a wavelet analysis technique [Torrence and Compo, 1998]. An example of this wavelet analysis technique applied to a radiosonde profile used in this paper can be seen in Figure 3. Four wave features with different scales can be resolved in Figure 3. This technique allows the temperature and wind perturbations for each individual wave to be determined from the reconstruction of the individual wave packets [Moffat-Griffin et al., 2011; Zink and Vincent, 2001]. Where individual waves in the wavelet analysis are close in height-scale and/or vertical wavenumber-scale space, the technique outlined in Zink and Vincent [2001] evenly divides the variance values in the overlap region between the waves before reconstructing their perturbation parameters. These individual wave perturbations are then used to determine the gravity wave parameters. This technique has been used successfully in a previous radiosonde study [Moffat-Griffin et al., 2011].
[13] To determine the vertical propagation direction of the gravity wave, a hodograph for each individual wave is produced. An example of a typical hodograph can be seen in Moffat-Griffin et al. [2011]. In the Southern (Northern) Hemisphere, an anticlockwise (clockwise) rotation of the wind vector in the hodograph corresponds to the gravity wave having upward (downward) energy propagation and downward (upward) phase velocity [Hirota and Niki, 1985].

[14] In this paper, the seasonal variation of the vertical direction of propagation of gravity waves is examined in relation to the seasonal variation in gravity wave energy and potential sources of gravity waves are examined.

\section{Results}

\subsection{Energy}

[15] Figure 4 shows the climatology of the monthly mean potential, kinetic, and total gravity wave energy per unit mass from 2002 to 2010 over MPA between $15 \mathrm{~km}$ and $22 \mathrm{~km}$ altitude. The total energy per unit mass (or energy density) was determined using the same technique used in Moffat-Griffin et al. [2011] to allow comparison with existing studies.

[16] There is a distinct seasonal variation in the energy densities with the total energy density peaking at $1.65 \pm 0.24 \mathrm{~J} / \mathrm{kg}$ in April and then decreasing to a minimum of $0.88 \pm 0.13 \mathrm{~J} / \mathrm{kg}$ in August before increasing again toward the end of the year. The errors represent the log-normal standard deviation of the data for each month. Both the kinetic and potential energy density follow the same seasonal variation over the year, although the kinetic energy density variation is much larger than the potential energy density variation $(0.61 \mathrm{~J} / \mathrm{kg}$ over the year compared to $0.16 \mathrm{~J} / \mathrm{kg}$ ). Previous studies of gravity wave activity show a peak in energy density over the Antarctic continent around the time of the September equinox [Yoshiki and Sato, 2000], over the Antarctic Peninsula around both equinoxes [Moffat-Griffin et al., 2011] and over Macquarie Island (which is at a similar latitude to MPA) during winter with a smaller peak around the autumn equinox [Zink and Vincent, 2001]. The seasonal variation seen over MPA is different than that in the Antarctic and midlatitude studies suggesting different influences on the seasonal variation in gravity wave energy density in this latitude, longitude, and altitude range.

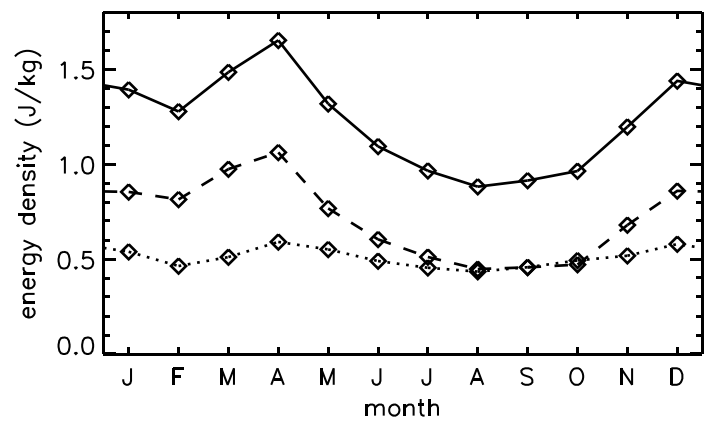

Figure 4. The monthly mean energy density between $15 \mathrm{~km}$ and $22 \mathrm{~km}$ altitude above MPA from 2002 to 2010 . The solid line is the total energy, the dashed line is kinetic energy, and the dotted line is potential energy. 
a)

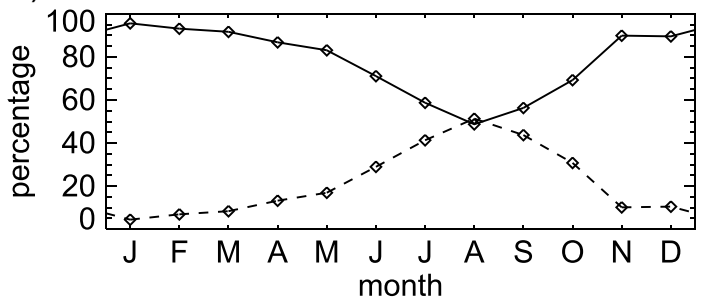

b)

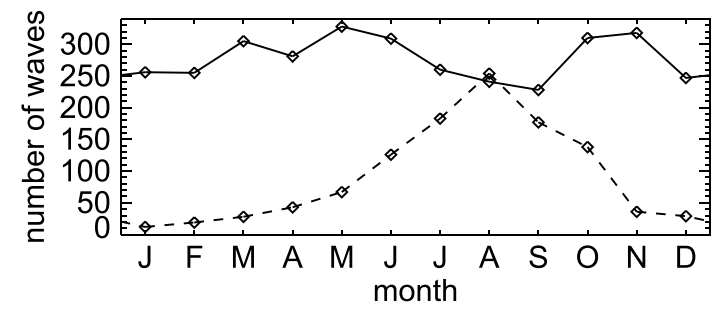

Figure 5. The (top) percentage and (bottom) number of upward and downward propagating gravity waves per month between $15 \mathrm{~km}$ and $22 \mathrm{~km}$ altitude above MPA from 2002 to 2010 . The solid lines represent upward propagating waves, the dashed lines downward propagating waves.

\subsection{Vertical Propagation Direction}

[17] Figure 5 shows the seasonal variation of the percentage (a) and number (b) of upward and downward propagating gravity waves over MPA respectively. Figure 5a appears to show a similar seasonal percentage variation in vertical propagation direction to that seen over Rothera [Moffat-Griffin et al., 2011], with a decrease (increase) in upward (downward) propagating waves during the winter months. Figure $5 \mathrm{~b}$ shows that the increase in downward propagating waves is pronounced (a 20-fold increase) and peaks during August, while there is a relatively small reduction (a decrease of about a third) in the number of upward propagating waves during June to September. Although the percentage seasonal variation is similar to that seen at Rothera, the seasonal variation in number (not shown) at Rothera is very different with a larger decrease in upwardly propagating waves and a small increase in downwardly propagating waves throughout the winter and spring equinox period. Modeling studies of the stratospheric region near to MPA do suggest an increase in downward propagating gravity waves during the month of August [Sato et al., 2012], which is attributed to partially reflected mountain waves. During periods of gravity wave reflection we would expect to see a reduction in energy density of the gravity waves. This is due to the destructive interference of the reflected waves, reducing the amplitudes of perturbations in the winds and temperature observations. For the case of MPA, the maximum in downward propagating waves coincides with a minimum in gravity wave energy density.

\section{Discussion}

[18] To understand the seasonal variations in the gravity wave energy density and vertical propagation directions in the lower stratosphere above MPA, the variations in the likely gravity wave sources need to be examined. Tropospheric sources such as mountain waves and freely propagating gravity waves from storms, in addition to waves generated by the stratospheric polar vortex, are examined below.

\subsection{Tropospheric Gravity Wave Sources}

[19] The Falkland Islands are not especially mountainous, with the Wickham Heights, the highest region on the islands, having peaks of $\sim 700 \mathrm{~m}$, located just to the north of MPA. Although not especially high, this region is still responsible for significant orographic-related turbulence which could propagate into the lower stratosphere. The large mountains of the Andes (which can reach heights of $6 \mathrm{~km}$ ) are $\sim 1000 \mathrm{~km}$ away and the mountain waves from these may also contribute to the stratospheric gravity wavefield above MPA due to their leeward propagation [Preusse et al., 2002; Sato et al., 2012]. The weather regime in the Falkland Islands is influenced by the proximity of the Andes to the west and the Antarctic Peninsula some $1100 \mathrm{~km}$ to the south. The predominant wind direction over the Falkland Islands is westerly but the particular direction and speed on any given day will have a marked effect on the weather at MPA and thus the wind flow over the local mountains [Turner and Pendlebury, 2004].

[20] To investigate the possible influence of mountain waves (orographic gravity waves generated by wind flow over the local orography/mountains) on the variation of energy density in the lower stratosphere above MPA, the correlation between the gravity wave activity in this region and the mean wind speed at different tropospheric altitudes ranges has been examined [Yoshiki and Sato, 2000]. The kinetic energy density determined from the radiosonde data is used as an estimate of the level of gravity wave activity. The mean wind speed during 2002 to 2010 is taken from the NCEP/NCAR reanalysis data set. Two altitude ranges over different sites are examined: (a) between $925 \mathrm{hPa}$

(a)

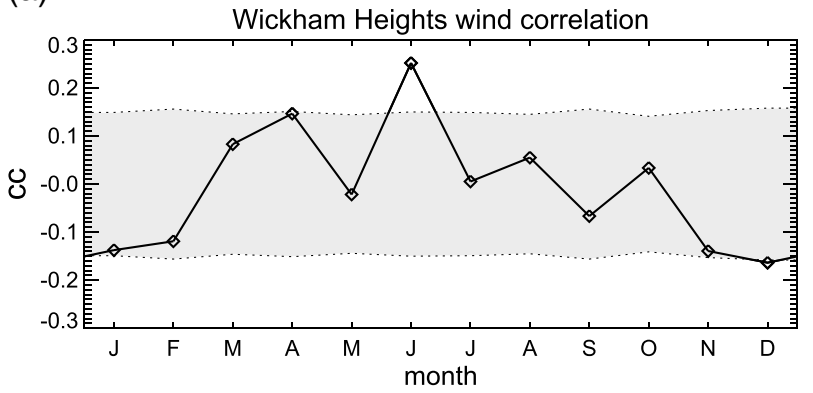

(b)

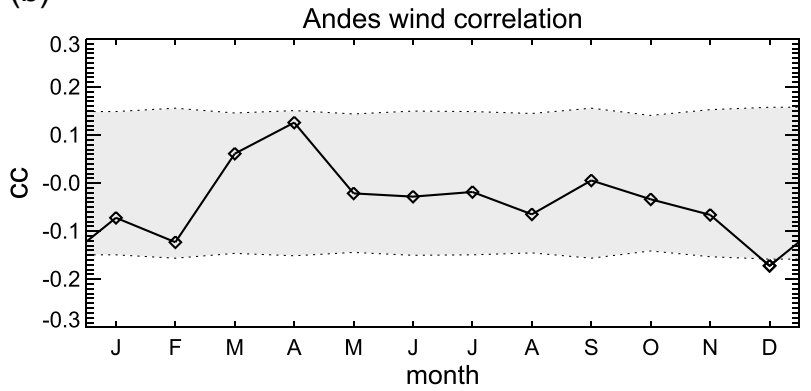

Figure 6. Correlations between the winds above the (a) Wickham Heights and (b) Andes with the stratospheric gravity wave kinetic energy density between 15 and $22 \mathrm{~km}$ altitude above MPA. 
$(\sim 0.76 \mathrm{~km})$ and $850 \mathrm{hPa}(\sim 1.4 \mathrm{~km})$ above the Wickham Heights and (b) between $600 \mathrm{hPa}(\sim 4.2 \mathrm{~km})$ and $500 \mathrm{hPa}$ $(\sim 5.5 \mathrm{~km})$ above the Andes Mountain range to the west of the Falkland Islands. Figure 6 shows the correlation between the monthly mean stratospheric kinetic energy density between $15 \mathrm{~km}$ and $22 \mathrm{~km}$ and monthly mean wind speed for Wickham Heights (a) and the Andes (b). The correlation is significant at $95 \%$ outside the shaded region; this significance level was determined using the $t$ test. Figure 6 a shows that there is a significant correlation during June between the gravity wave activity and the wind above the Wickham Heights; Figure $6 \mathrm{~b}$ does not show any significant correlation between gravity wave activity and the wind above the Andes. Although there is an occurrence of statistically significant correlation in Figure $6 \mathrm{a}$, the correlation values are low for both plots, implying no strong link between the variation of mountain wave activity and the seasonal variation of energy density in the lower stratosphere above MPA.

[21] The extent of vertical propagation by a gravity wave is determined by the background wind. The gravity wave is critically filtered when its horizontal velocity matches that of the background wind. The seasonal variation of critical level filtering on both freely propagating gravity waves and mountain waves will influence the gravity wave energy density reaching the lower stratosphere.

[22] The literature has shown that as wind rotations go from 0 to 180 degrees there is a steady decrease in gravity wave energy as more waves are critically filtered [Baumgaertner and McDonald, 2007]. In accordance with previous work, we will take wind rotations over a height range that are greater than 90 degrees as critically filtering mountain waves [Baumgaertner and McDonald, 2007; Whiteway et al., 1997; Yamashita et al., 2009]. To determine the critical level filtering above MPA daily 2006 NCAR/ NCEP wind velocity data (derived using the technique outlined in [Kalnay et al., 1996]) are used to examine the amount of wind rotation from the height of the local mountains up to $15 \mathrm{~km}$ altitude. The data from other years are also used (not shown) and no large differences between them and the 2006 results were found. Figure 7 shows the monthly averaged (and daily) wind rotation, determined using a logarithmic mean as the data have a log-normal distribution, between $1 \mathrm{~km}$ and $15 \mathrm{~km}$ altitude above MPA. Average wind rotations of the order of 45 degrees and above are seen during June, decreasing to around 30 degrees during July, although there are daily values above 90 degrees through the year. For the rest of the year, the average values vary between 10 and 25 degrees, with the lowest values being around the equinoxes and early summer. The daily values in Figure 7 show that although there are more days with a high wind rotation during the months mentioned previously, there are still a large number of lower wind rotation events during that month, so the filtering is not absolute. Overall, Figure 7 shows that any mountain waves generated by the Wickham Heights less frequently reach $15 \mathrm{~km}$ during the winter months but that there is a greater chance of them reaching this altitude during the equinoxes and summer months.

[23] Mountain waves are not a constant source over time and are intermittent in nature, with their prevalence depending on local weather conditions. This can help explain why Figure 7 shows that mountain waves can be expected to reach $15 \mathrm{~km}$, yet the correlations shown in Figure 6 do not show

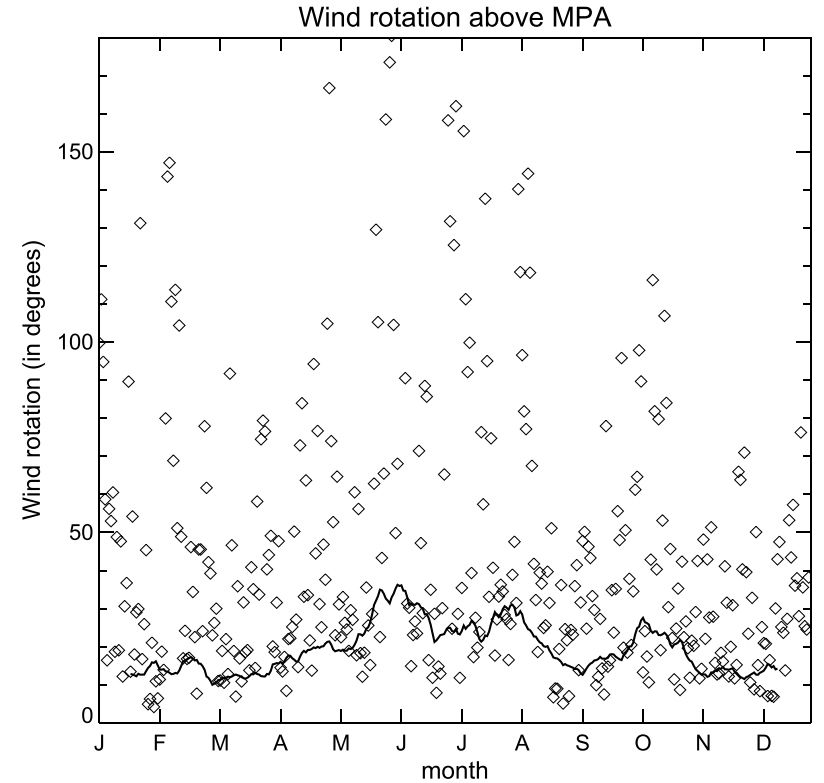

Figure 7. Daily and monthly wind rotations above MPA from 1 to $15 \mathrm{~km}$ altitude. The solid line is the monthly mean; the diamonds are the daily values. The wind rotation values were determined using NCEP/NCAR reanalysis data from 2006.

large values for the same times of year. These results suggest that although local mountain waves can reach our observing altitude range, they may be infrequent or not strong enough to contribute significantly to the seasonal variation in gravity wave energy density.

[24] The data used in this study are not suitable for determining whether mountain waves from the Andes are influencing the gravity wave energy density in the lower stratosphere. Work in the literature suggests that they do propagate laterally and can influence the stratosphere, albeit at higher altitudes than the region examined in this paper [Alexander and Teitelbaum, 2011; Preusse et al., 2002; Sato et al., 2012]. There is evidence that the downward propagating gravity waves seen in this region could be contributed to by partial reflection of the large amplitude Andes mountain waves from a quick increase in static stability at higher altitudes (around $10 \mathrm{hPa}$ ) or nonlinear effects related to primary orographic wave breaking [Bacmeister and Schoeberl, 1989; Sato et al., 2012]. However, it is not possible to determine how much these reflected orographic waves would contribute to the results seen in Figure 5 using the data from the radiosondes.

[25] To determine the critical level filtering on freely propagating gravity waves, a simple modeling approach is undertaken [Garcia and Solomon, 1985; Taylor et al., 1993; Yamashita et al., 2009]. Gravity waves (uniformly distributed in all propagation directions and with ground-based horizontal phase speeds between 0 and $40 \mathrm{~m} / \mathrm{s}$ ) are simulated traveling upward through a background wind field. The background wind field above MPA was simulated again using NCEP/ NCAR analysis wind velocity data from 2006. Using this method, we can determine the probability of freely propagating gravity waves reaching the altitude range of the radiosonde observations, $15-22 \mathrm{~km}$. Figure 8 shows the monthly mean 


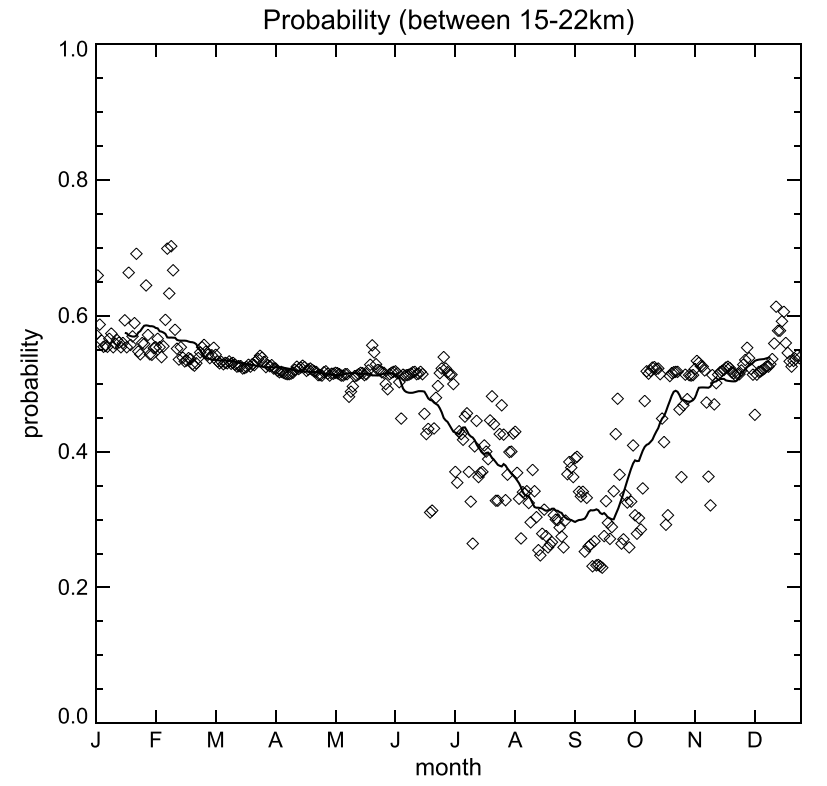

Figure 8. The mean probability of freely propagating gravity waves reaching $15-22 \mathrm{~km}$ altitude. Solid line is the monthly average; diamonds are the daily values.

probability of freely propagating waves reaching $15-22 \mathrm{~km}$ altitude. We see that the likelihood of freely propagating gravity waves reaching $15 \mathrm{~km}$ altitude is between $50 \%$ and $60 \%$ from November to June. During July to October, the probability dips to around $30 \%$. This indicates that during the late winter and early spring, freely propagating gravity waves are less likely to influence the gravity wave energy density in the lower stratosphere above MPA.

[26] The results shown in Figures 7 and 8 explain those shown in Figure $5 b$, where a decrease in the number of upward propagating waves is seen between June and October. This decrease is due to the critical level filtering of upward propagating waves (both mountain and freely propagating) from the troposphere.

[27] A known source of tropospheric freely propagating gravity waves is weather systems, especially storms. There are many examples in the literature of observational and modeling studies of gravity waves generated by weather systems [Alexander et al., 1995; Fovell et al., 1992; Kuester et al., 2008; Pandya and Durran, 1996; Sato et al., 1995; Vadas et al., 2009]. There are no detailed studies concerning the gravity waves generated by the circumpolar storm track in Antarctica, although a study of inertia gravity waves over Macquarie Island links variations in wave activity to a common synoptic pattern, [Guest et al., 2000]. Due to the location of the Falkland Islands, they are frequently buffeted by storms, and their associated weather fronts, from two main directions: The Antarctic circumpolar storm track which expands to encompass the region at certain times of the year [Hoskins and Hodges, 2005], and a known preferred region for cyclogenesis [Jones and Simmonds, 1993] over the Andes which results in storms moving down toward the Falkland Islands. As these storms spend significant time over water, they are associated with extensive regions of cloud by the time they make land fall, making them potentially significant generators of gravity waves [Fovell et al., 1992].
[28] The storm frequency and intensity at and close to the Falkland Islands region have been presented as part of studies in the literature that examine the Southern Hemisphere storm tracks, [e.g., Hoskins and Hodges, 2005; Inatsu and Hoskins, 2004; Jones and Simmonds, 1993, 1994]. A clear seasonal variation in the intensity of storms that are in the vicinity of the Falkland Islands is shown in Figure 10 of Hoskins and Hodges [2005], with the storm intensity around the Falkland Islands peaking during late summer and autumn. This is the same time of year that the increase in gravity wave energy density is seen over MPA. Figure 8 also shows that during this time of year we would expect a higher proportion of freely propagating gravity waves to reach $15 \mathrm{~km}$ and above. Although not a statistically proven relationship, it seems likely that intense large storms in the region of the Falkland Islands during the late summer and autumn are related to the increase in gravity wave energy density that is seen in the radiosonde data. Further investigation of this conclusion is outside the scope of this paper and is the subject of a future study.

\subsection{Stratospheric Polar Vortex}

[29] The wintertime polar vortex is a known source of gravity waves in the Antarctic region; many studies have reported an enhancement of gravity wave energy density (and an increase in the numbers of upward and downward propagating gravity waves) when it is close by and especially when it breaks up in the springtime [Baumgaertner and McDonald, 2007; Moffat-Griffin et al., 2011; Sato and Yoshiki, 2008; Yamashita et al., 2009; Yoshiki et al., 2004]. The polar vortex can also act to partially reflect upward propagating gravity waves downward [Sato et al., 2012].

[30] The proximity of the polar vortex edge to MPA is examined with relation to the seasonal variation in the

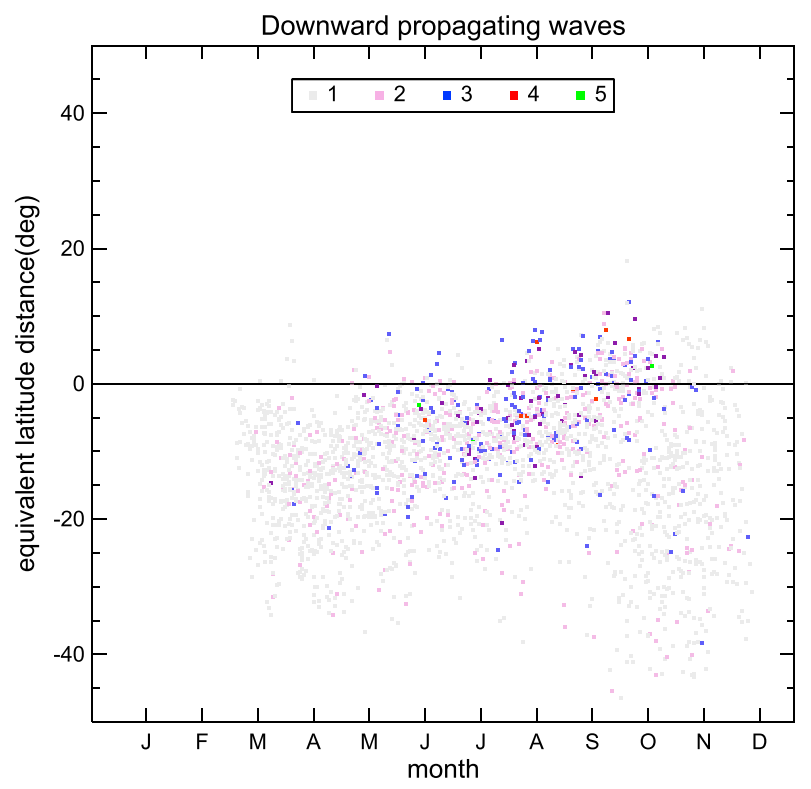

Figure 9. The equivalent latitude position of the edge of the polar vortex (at $21 \mathrm{hPa}$ ) from MPA, 0 degrees equivalent latitude, from 2002 to 2010 is represented with a square. The number of downward propagating gravity waves for each radiosonde profile on a given day determines the color of the square. 
numbers of downward propagating gravity waves and the energy density. The position of the vortex edge is given in distance in equivalent latitude from the vortex edge, calculated using the criteria developed by Nash et al. [1996], with positive values indicating that the measurement location is under the polar vortex. Equivalent latitude is the latitude that would encompass the same area between it and the pole as a potential vorticity (PV) contour [Butchart and Remsberg, 1986]. For this paper, equivalent latitude was calculated from the GEOS-5 MERRA reanalysis [Rienecker et al., 2011] PV fields and interpolated to the station location as described by Manney et al. [2007]. Meteorological fields including the distance from the polar vortex edges were provided on 61 different pressure levels from $1000 \mathrm{hPa}$ to $0.01 \mathrm{hPa}$; the vortex edge is identified on all levels where it is meaningful (that is, in and above the lowermost stratosphere, see Manney et al. [2007]). The vortex edge identification method is reliable for the lower to middle stratosphere during winter, but is less reliable during the autumn (as the vortex develops) and spring (when the vortex breaks down) [Manney et al., 2007].

[31] Figure 9 shows the equivalent latitude position of the polar vortex edge over the years 2002-2010 at $21 \mathrm{hPa}$ ( $\sim 24 \mathrm{~km}$ altitude) plotted as squares. The pressure level of $21 \mathrm{hPa}$ is used as it is the first level in the reanalysis data provided that is above $22 \mathrm{~km}$ altitude. The color of each square is determined by the number of downward propagating gravity waves that were detected in the radiosonde analysis for that day (see scale associated with each plot). Figure 9 shows that there is a clustering of profiles with a high number of downward propagating gravity waves when the vortex edge is close to MPA. This proximity occurs during July-August, the same time frame as the increase in number of downward propagating waves shown in the results in Figure $5 \mathrm{~b}$.

[32] When the edge of the polar vortex (at $21 \mathrm{hPa}$ ) is close to MPA during July-August, an increase in the number of downwardly propagating gravity waves is seen at the same time, indicating that the proximity of the polar vortex edge contributes to the increase in these gravity waves.

[33] However, an increase in gravity wave energy density is not seen during July-August (Figure 4) when the polar vortex edge is in close proximity to MPA. This would appear to disagree with existing gravity wave studies that see an increase in gravity wave energy in the stratosphere in proximity to the polar vortex edge. Gravity wave studies in the literature that cover the Falkland Island region offer a possible explanation for this apparent contradiction, [Alexander et al., 2009; Sato et al., 2012]. These studies (using satellite data and modeling results, respectively) examine results that cover the Falkland Islands region and show there is an increase in gravity wave activity around August but it is strongest at higher altitudes than those used in our study. If the entire height range of available radiosonde data is used to determine the gravity wave energy density, despite the limited data at high altitudes, there is evidence of an increase in energy above $30 \mathrm{~km}$ (not shown) around August-September, with the peak in energy over autumn months disappearing at these altitudes. This supports the idea that the restricted altitude range of this study is the reason the spring peak in energy density is not observed. It should also be taken into account that, because of the observational filtering, radiosonde observations only capture a small part of the gravity wave spectrum that is different from the portions observed by satellites and other instrumentation
[Alexander, 1998]. Additionally, the polar vortex can act as a region of reflection above the altitude region studied in this paper, and can thus contribute to the increase in downward propagating waves observed at the same time as the minimum in energy.

\section{Summary}

[34] The seasonal variation in gravity wave energy density and vertical direction of propagation in the lower stratosphere above MPA on the Falkland Islands between 2002 and 2010 has been studied using data from over 2100 radiosonde observations. The large seasonal variations in several different gravity wave sources make the Falkland Islands a useful location for better understanding their relative influence on the gravity wavefield throughout the year. The sources examined in this paper are orography, storms, and the edge of the stratospheric polar vortex.

[35] The gravity wave energy density exhibits a distinct seasonal variation with a peak occurring in April, just after the autumn equinox. This increase in energy density is attributed to gravity waves from tropospheric sources, especially those generated by storms passing over/close to the Falkland Islands that are more frequent during the late summer and autumn concurrent with the increase in energy density. Although many local mountain waves would be able to reach our observational altitude of $15 \mathrm{~km}$ at certain times of the year (depending on the amount of critical level filtering), the low correlation values shown in Figure 6 indicate that they are not a significant contributor to the observed levels of gravity wave activity. The autumn peak in gravity wave energy density in the lower stratosphere above MPA is a new result: most of the previous literature reporting an increase in stratospheric gravity wave energy densities during the spring. The autumn peak in gravity wave energy density does, however, occur only in the restricted altitude range that was the focus of this study. The limited radiosonde data at higher altitudes suggest an increase in gravity wave energy density during the spring, consistent with previous studies.

[36] The seasonal variations in the numbers of upward and downward propagating waves seen in the lower stratosphere above MPA have been attributed, respectively, to the seasonal variation in critical level filtering of mountain and tropospheric freely propagating gravity waves and to the proximity of the stratospheric polar vortex to MPA.

[37] These results show a peak in gravity wave energy density in the autumn over MPA that has not previously been reported. It is present over the entire observational altitude range used in this paper. Our results also link the proximity of the stratospheric polar vortex edge to an observed increase in downward propagating gravity waves and decrease in gravity wave energy density in August. The Falkland Islands lie within the gravity wave hot spot located over the Southern Andes/Drake Passage/Antarctic Peninsula region, and this paper has identified several likely sources of gravity waves that are important in determining the amount of gravity wave activity in the lower stratosphere in this region above MPA.

[38] This new work will lead onto further detailed studies of the gravity wave activity variation and intermittency above MPA, from the troposphere into the lower stratosphere. Studies combining radiosonde gravity wave results with storm 


\section{MOFFAT-GRIFFIN ET AL.: GRAVITY WAVE ENERGY ABOVE THE FALKLANDS}

statistics will be essential to help quantify the role of storms as a gravity wave source in this region. Research on further understanding the gravity wave sources and their variability in this region of enhanced gravity wave activity is essential to understand their influence on other atmospheric regions.

[39] Acknowledgments. We would like to thank the Met Office for their assistance and guidance in using the radiosonde data set and the BADC for making the data publically available. Thanks to NASA's Global Modelling and Assimilation Office for providing the MERRA reanalysis used in defining polar vortex diagnostics. NCEP Reanalysis data were provided by the NOAA/OAR/ESRL PSD, Boulder, Colorado, USA (http:// www.esrl.noaa.gov/psd/). Work at the Jet Propulsion Laboratory, California Institute of Technology was done under contract with the National Aeronautics and Space Administration.

\section{References}

Alexander, M. J. (1998), Interpretations of observed climatological patterns in stratospheric gravity wave variance, J. Geophys. Res., 103, 8627-8640.

Alexander, M. J., and H. Teitelbaum (2011), Three-dimensional properties of Andes mountain waves observed by satellite: A case study, J. Geophys. Res., 116, D23110, doi:10.1029/2011JD016151.

Alexander, M. J., J. R. Holton, and D. R. Durran (1995), The gravity-wave response above deep convection in a squall line simulation, J. Atmos. Sci., 52(12), 2212-2226.

Alexander, M. J., T. Tsuda, and R. A. Vincent (2002), Latitudinal Variations Observed in Gravity Waves with Short Vertical Wavelengths, J. Atmos. Sci., 59(8), 1394-1404.

Alexander, S. P., A. R. Klekociuk, and T. Tsuda (2009), Gravity wave and orographic wave activity observed around the Antarctic and Arctic stratospheric vortices by the COSMIC GPS-RO satellite constellation, J. Geophys. Res., 114, D17103, doi:10.1029/2009JD011851.

Alexander, M. J., et al. (2010), Recent developments in gravity-wave effects in climate models and the global distribution of gravity-wave momentum flux from observations and models, Q. J. R. Meteorol. Soc., 136(650), 1103-1124.

Bacmeister, J. T., and M. R. Schoeberl (1989), Breakdown of Vertically Propagating Two-Dimensional Gravity Waves Forced by Orography, J. Atmos. Sci., 46(14), 2109-2134.

BADC (2012), UK High Resolution Radiosonde Data, edited by U. M. Office, NCAS British Atmospheric Data Centre, BADC.

Baumgaertner, A. J. G., and A. J. McDonald (2007), A gravity wave climatology for Antarctica compiled from Challenging Minisatellite Payload/Global Positioning System (CHAMP/GPS) radio occultations, J. Geophys. Res., 112, doi:10.1029/2006JD007504.

Butchart, N., and E. E. Remsberg (1986), The area of the stratospheric polar vortex as a diagnostic for tracer transport on an isentropic surface, J. Atmos. Sci., 43(13), 1319-1339.

Fovell, R., D. Durran, and J. R. Holton (1992), Numerical Simulations of Convectively Generated Stratospheric Gravity Waves, J. Atmos. Sci., 49(16), 1427-1442.

Garcia, R. R., and S. Solomon (1985), The Effect of Breaking Gravity Waves on the Dynamics and Chemical Composition of the Mesosphere and Lower Thermosphere, J. Geophys. Res., 90(D2), 3850-3868.

Guest, F. M., M. J. Reeder, C. J. Marks, and D. J. Karoly (2000), InertiaGravity Waves Observed in the Lower Stratosphere over Macquarie Island, J. Atmos. Sci., 57(5), 737-752.

Hei, H., T. Tsuda, and T. Hirooka (2008), Characterisitcs of atmospheric gravity wave activity in the polar regions revealed by GPS radio occulation data with CHAMP, J. Geophys. Res., 113, doi:10.1029/ 2007JD008938.

Hirota, I., and T. Niki (1985), A statistical study of inertia-gravity waves in the middle atmosphere, J. Meteor. Soc. Japan., 63, 1055-1066.

Hoskins, B. J., and K. I. Hodges (2005), A New Perspective on Southern Hemisphere Storm Tracks, J. Clim., 18(20), 4108-4129.

Inatsu, M., and B. J. Hoskins (2004), The Zonal Asymmetry of the Southern Hemisphere Winter Storm Track, J. Clim., 17(24), 4882-4892.

Jones, D. A., and I. Simmonds (1993), A climatology of SouthernHemisphere extratropical cyclones, Clim. Dyn., 9(3), 131-145.

Jones, D. A., and I. Simmonds (1994), A climatology of SouthernHemisphere anticyclones, Clim. Dyn., 10(6-7), 333-348.

Kalnay, E., et al. (1996), The NCEP/NCAR 40-Year Reanalysis Project, Bull. Am. Meteorol. Soc., 77(3), 437-471.
Kim, Y. J., S. D. Eckermann, and H. Y. Chun (2003), An overview of the past, present and future of gravity wave drag parametrization for numerical climate and weather prediction models, Atmosphere-ocean, 41(1), 65-98.

Kuester, M. A., M. J. Alexander, and E. A. Ray (2008), A model study of gravity waves over Hurricane Humberto (2001), J. Atmos. Sci., 65(10), 3231-3246.

Manney, G. L., et al. (2007), Solar occultation satellite data and derived meteorological products: Sampling issues and comparisons with Aura Microwave Limb Sounder, J. Geophys. Res., 112, D24S50, doi:10.1029/2007JD008709.

McLandress, C., M. J. Alexander, and D. L. Wu (2000), Microwave Limb Sounder observations of gravity waves in the stratosphere: A climatology and interpretation, J. Geophys. Res., 105(D9), 11,947-11,967.

Mobbs, S. D., S. B. Vosper, P. F. Sheridan, R. Cardoso, R. R. Burton, S. J. Arnold, M. K. Hill, V. Horlacher, and A. M. Gadian (2005), Observations of downslope winds and rotors in the Falkland Islands, $Q$. J. R. Meteorol. Soc., 131(605), 329-351.

Moffat-Griffin, T., R. E. Hibbins, M. J. Jarvis, and S. R. Colwell (2011), Seasonal variations of gravity wave activity in the lower stratosphere over an Antarctic Peninsula station, J. Geophys. Res., 116, D14111, doi:10.1029/2010JD015349.

Pandya, R. E., and D. R. Durran (1996), The influence of convectively generated thermal forcing on the mesoscale circulation around squall lines, J. Atmos. Sci., 53(20), 2924-2951.

Pirscher, B., U. Foelsche, M. Borsche, G. Kirchengast, and Y. H. Kuo (2010), Analysis of migrating diurnal tides detected in FORMOSAT-3/ COSMIC temperature data, J. Geophys. Res., 115, D14108, doi:10.1029/ 2009JD013008.

Preusse, P., A. Dörnbrack, S. D. Eckermann, M. Riese, B. Schaeler, J. T. Bacmeister, D. Broutman, and K. U. Grossmann (2002), Space-based measurements of stratospheric mountain waves by CRISTA 1. Sensitivity, analysis method, and a case study, J. Geophys. Res., 107(D23), 8178, doi:10.1029/2001JD000699.

Preusse, P., S. D. Eckermann, M. Ern, J. Oberheide, R. H. Picard, R. G. Roble, M. Riese, J. M. Russell, and M. G. Mlynczak (2009), Global ray tracing simulations of the SABER gravity wave climatology, J. Geophys. Res., 114, D08126, doi:10.1029/2008JD011214.

Rienecker, M. M., et al. (2011), MERRA: NASA's Modern-Era Retrospective Analysis for Research and Applications, J. Clim., 24(14), 3624-3648.

Sato, K., and M. Yoshiki (2008), Gravity wave generation around the Polar Vortex in the stratosphere revealed by 3-hourly radiosonde observations at Syowa station, J. Atmos. Sci., 65, 3719-3735.

Sato, K., H. Hashiguchi, and S. Fukao (1995), Gravity waves and turbulance associated with cumulus convection observed with the UHF/VHF clear-air doppler radars, J. Geophys. Res., 100(D4), 7111-7119.

Sato, K., S. Tateno, S. Watanabe, and Y. Kawatani (2012), Gravity wave characteristics in the Southern Hemisphere revealed by a highresolution middle atmosphere general circulation model, J. Atmos. Sci., 69, 1378-1396.

Sheridan, P. F., and S. B. Vosper (2005), Numerical simulations of rotors, hydraulic jumps and eddy shedding in the Falkland Islands, Atmos. Sci. Lett., 6(4), 211-218.

Smout, R., J. Nash, T. Hewison, and M. Smees (2005), Results of the RS92 acceptance test performed by the Met Office (UK)Rep., WMO.

Taylor, M. J., E. H. Ryan, T. F. Tuan, and R. Edwards (1993) Evidence of preferential directions for gravity wave propagation due to wind filtering in the middle atmosphere, J. Geophys. Res., 98(A4), 6047-6057.

Torrence, C., and G. P. Compo (1998), A practical guide to wavelet analysis, Bull. Am. Meteorol. Soc., 79(1), 61-78.

Turner, J., and S. Pendlebury (Eds.) (2004), The International Antarctic Weather Forecasting Handbook, 663 pp., British Antarctic Survey, Cambridge.

Vadas, S. L., J. Yue, C.-Y. She, P. A. Stamus, and A. Z. Liu (2009), A model study of the effects of winds on concentric rings of gravity waves from a convective plume near Fort Collins on 11 May 2004, J. Geophys. Res., 114, D06103, doi:10.1029/2008JD010753.

Vincent, R. A., and M. J. Alexander (2000), Gravity waves in the tropical lower stratosphere: An observational study of seasonal and interannual variability, J. Geophys. Res., 105, 17,971-917,982.

Vincent, R. A., S. J. Allen, and E. Eckermann (1997), Gravity-wave parameters in the lower stratosphere, in Gravity Wave Processes: Their Parameterization in Global Climate Models, edited by K. Hamilton, pp. 7-25, Springer-Verlag, New York.

Vosper, S. B. (2004), Inversion effects on mountain lee waves, Q. J. R. Meteorol. Soc., 130(600), 1723-1748. 


\section{MOFFAT-GRIFFIN ET AL.: GRAVITY WAVE ENERGY ABOVE THE FALKLANDS}

Whiteway, J. A., T. J. Duck, D. P. Donovan, J. C. Bird, S. R. Pal, and A. I. Carswell (1997), Measurements of gravity wave activity within and around the Arctic stratospheric vortex, Geophys. Res. Lett., 24(11), 1387-1390.

Wu, D. L., and J. H. Jiang (2002), MLS observations of atmospheric gravity waves over Antarctica, J. Geophys. Res., 107(D24), doi:10.1029/ 2002JD002390.

Yamashita, C., X. Chu, H.-L. Liu, P. J. Espy, G. J. Nott, and W. Huang (2009), Stratospheric gravity wave characteristics and seasonal variations observed by lidar at the South Pole and Rothera, Antarctica, J. Geophys. Res., 114, D12101, doi:10.1029/2008JD011472.
Yoshiki, M., and K. Sato (2000), A statistical study of gravity waves in the polar regions based on operational radiosonde data, J. Geophys. Res., 105(D14), 17,995-918,011.

Yoshiki, M., N. Kizu, and K. Sato (2004), Energy enhancements of gravity waves in the Antarctic lower stratosphere associated with variations in the polar vortex and tropospheric disturbances, J. Geophys. Res., 109, D23104, doi:10.1029/2004JD004870.

Zink, F., and R. A. Vincent (2001), Wavelet analysis of stratospheric gravity wave packets over Macquarie Island 1. Wave parameters, J. Geophys. Res., 106, 10,275-210,288. 